\section{Dopamine D1 and D2 receptor immunoreactivities in the arcuate-median eminence complex and their link to the tubero-infundibular dopamine neurons}

\author{
W. Romero-Fernandez, ${ }^{1,2}$ \\ D.O. Borroto-Escuela, ${ }^{1}$ \\ V. Vargas-Barroso, ${ }^{3}$ \\ M. Narváez, ${ }^{4}$ M. Di Palma, ${ }^{1,5}$ L.F. Agnati, \\ J. Larriva Sahd, ${ }^{3}$ K. Fuxe \\ 'Department of Neuroscience, Karolinska \\ Institute, Stockholm, Sweden \\ 2Faculty of Health Sciences, Technical \\ University of Ambato, Ecuador \\ ${ }^{3}$ Institute of Neurobiology, National \\ Autonomous University of Mexico, \\ Campus Juriquilla, Mexico \\ ${ }^{4}$ University of Malaga, Andalucia Tech, \\ Faculty of Medicine, Spain \\ ${ }^{5}$ Department of Earth, Life and \\ Environmental Sciences, Section \\ of Physiology, Carlo Bo University \\ of Urbino, Italy
}

\section{Abstract}

Dopamine D1 and D2 receptor immunohistochemistry and Golgi techniques were used to study the structure of the adult rat arcuatemedian eminence complex, and determine the distribution of the dopamine D1 and D2 receptor immunoreactivities therein, particularly in relation to the tubero-infundibular dopamine neurons. Punctate dopamine D1 and D2 receptor immunoreactivities, likely located on nerve terminals, were enriched in the lateral palisade zone built up of nerve terminals, while the densities were low to modest in the medial palisade zone. A codistribution of dopamine D1 receptor or dopamine D2 receptor immunoreactive puncta with tyrosine hydroxylase immunoreactive nerve terminals was demonstrated in the external layer. Dopamine D1 receptor but not dopamine D2 receptor immnunoreactivites nerve cell bodies were found in the ventromedial part of the arcuate nucleus and in the lateral part of the internal layer of the median eminence forming a continuous cell mass presumably representing neuropeptide Y immunoreactive nerve cell bodies. The major arcuate dopamine/ tyrosine hydroxylase nerve cell group was found in the dorsomedial part. A large number of tyrosine hydroxylase immunoreactive nerve cell bodies in this region demonstrated punctate dopamine D1 receptor immunoreactivity but only a few pre- sented dopamine D2 receptor immunoreactivity which were mainly found in a substantial number of tyrosine hydroxylase cell bodies of the ventral periventricular hypothalamic nucleus, also belonging to the tuberoinfundibular dopamine neurons. Structural evidence for projections of the arcuate nerve cells into the median eminence was also obtained. Distal axons formed horizontal axons in the internal layer issuing a variable number of collaterals classified into single or multiple strands located in the external layer increasing our understanding of the dopamine nerve terminal networks in this region. Dopamine D1 and D2 receptors may therefore directly and differentially modulate the activity and/or Dopamine synthesis of substantial numbers of tubero-infundibular dopamine neurons at the somatic and terminal level. The immunohistochemical work also gives support to the view that dopamine D1 receptors and/or dopamine D2 receptors in the lateral palisade zone by mediating dopamine volume transmission may contribute to the inhibition of luteinizing hormone releasing hormone release from nerve terminals in this region.

\section{Introduction}

It is widely accepted that axons arising from distinct nuclei in the hypothalamic and preoptic nuclei descend and terminate in the external layer of the median eminence. Information from these systems derive from the classical studies performed with the rapid Golgi technique and its variants, primarily in the newborn rat $^{1}$ and from the interaction between axon terminals from neurons in these nuclei within the external layer of the median eminence (ME). ${ }^{2-4}$ Tubero-infundibular dopamine (DA) neurons were discovered and shown to densely innervate the external layer of the ME. ${ }^{2}$ In the lateral palisade zone (LPZ) the DA terminals substantially overlap especially with the luteinizing hormone releasing hormone (LHRH) immunoreactive (IR) nerve terminals and likely inhibit LHRH secretion while in the medial palisade zone they may mainly release DA as a hypothalamic hormone into the portal vessels to inhibit prolactin secretion..$^{5-9}$ Based on these observations, the concept was introduced that transmitter and hypothalamic hormone identified nerve terminal networks in the external layer of the median eminence are organized in discrete compartments, called structural medianosomes, forming rostro-caudal strips. ${ }^{10,11}$ Modular arrangements were postulated in the overlap areas between structural medianosomes, called integrative medianosomes, which regulate the secretion of one or several hypothalamic hormones.,10,12-14
Correspondence: Prof. Kjell Fuxe, Department of Neuroscience, Karolinska Institute, Retzius väg 8,17177 Stockholm, Sweden.

Tel: +46.8.52487077 - Fax: +46.8.315721.

E-mail: Kjell.Fuxe@ki.se

Key words: Dopamine D1 and D2 receptors, tubero-infundibular dopamine neurons, dopamine receptor colocalization, arcuate-median eminence complex, volume transmission, luteinizing hormone releasing hormone.

Contributions: WRF, DOBE contributed equally to this work; JLS, KF, research theme definition; WRF, DOBE, VVB, MN, MDP, LFA, JLS, KF, methods and experiments design, laboratory experiments, the data analysis and results interpretation; VVB, JLS, co-design and co-working on the experiments with the Rapid-Golgi and Golgi-Cox techniques; WRF, DOBE, KF, co-design, analysis discussion, interpretation, and presentation of all immunohistochemistry experiments; KF, DOBE, MN, MDP, immunohistochemistry experiments design, quality assurance and control of each used antibody; KF, JLS, manuscript writing. All authors have contributed to, seen and approved the manuscript.

Acknowledgments: this work has been supported by a grant from the Swedish Research Council (04X-715) to KF; by grants from the Swedish Royal Academy of Sciences (Stiftelsen B. von Beskows Fond and Stiftelsen Hierta-Retzius stipendiefond) and Karolinska Institutets Forskningsstiftelser 2012 and 2013 to DOBE; WRF and DOBE belong to the Academia de Biólogos Cubanos.

Conflict of interests: the authors declare no conflict of interests.

Received for publication: 21 March 2014. Accepted for publication: 9 June 2014.

This work is licensed under a Creative Commons Attribution NonCommercial 3.0 License (CC BYNC 3.0).

CCopyright W. Romero-Fernandez et al., 2014

Licensee PAGEPress, Italy

European Journal of Histochemistry 2014; 58:2400 doi:10.4081/ejh.2014.2400

Previous research has given indications for the existence of dopamine D1 receptor (D1DR) and dopamine D2 receptor (D2DR) mechanisms in the median eminence proposed to be involved in the inhibitory regulation of LHRH release. ${ }^{15-17}$ In fact, the DA receptors may participate in the regulation of the integrative DA/LHRH medianosomes in the lateral palisade zone. .,13,14 $^{5}$

We provide support for this view in the current paper by the immunohistochemical demonstration of D1DR and D2DR immunoreactivities (IR) in tyrosine hydroxylase (TH) 
cell bodies of the arcuate region and in the medial and especially lateral palisade zone of the external layer of the median eminence of the rat. In the external layer they are codistributed to a large extent with TH immunoreactive nerve terminals but the D1DR and D2DR show a differential distribution. The Golgi techniques used give an increased understanding of the structure of the DA terminal networks formed. Based on these observations D1DR and D2DR mediated DA volume transmission (VT) likely exists in the external layer of the median eminence since synaptic contacts have not been demonstrated in this region. ${ }^{18,19}$

\section{Materials and Methods}

\section{Immunohistochemistry}

Three male Sprague-Dawley rats, 10-weekold, weighing $200-250 \mathrm{~g}$, were obtained from Charles River Laboratories (Sulzfeld, Germany). The animals were housed one week before experiments under a 12-h light/dark cycle, with ambient temperature of $21 \pm 2^{\circ} \mathrm{C}$, relative humidity of $50 \pm 5 \%$. Food and water were available ad libitum. Animals were maintained in accordance with guidelines from the Swedish National Board for Laboratory Animal and European Communities Council Directive (Cons 123/2006/3) guidelines for accommodation and care of Laboratory Animals. The animal experiments had been approved by the Stockholm North Animal Ethics Committee (Permit N496/12). In all the experiments, efforts were made to minimize the number of animals used and their suffering. Adult male Sprague-Dawley rats $(n=3)$ were perfused via aorta under deep pentobarbital anesthesia using $4 \%$ paraformaldehyde in $0.1 \mathrm{M}$ sodium phosphate buffer ( $\mathrm{pH}$ 6.9). Brains were removed and later sectioned.

The immunohistochemical procedure was performed as previously described. ${ }^{20}$ Briefly, rat cryostat sections on slides $(10 \mu \mathrm{m})$ were washed twice with Tris buffered saline (TBS), pH 7.4 containing $20 \mathrm{mM}$ glycine (buffer A) to quench the aldehyde groups. Then, after permeabilization with buffer A containing 0.5\% Triton X-100 for $30 \mathrm{~min}$, sections were treated with $10 \%$ fetal bovine serum (FBS) and $0.1 \%$ Triton X-100 in TBS (buffer B). After $2 \mathrm{~h}$ at room temperature, sections were singly or doubly immunostained with the indicated primary antibodies at $4{ }^{\circ} \mathrm{C}$ overnight, extensively washed with TBS containing $0.01 \%$ Tween-20, and stained with the indicated fluorescence labelled secondary antibodies for $1 \mathrm{~h}$ at room temperature. The cryostat sections on slides were rinsed in TBS containing $0.01 \%$ Tween20 , mounted in a Vectashield immunofluorescence medium (Vector Laboratories,
Peterborough, UK) and visualized with a Leica SP2 confocal microscope (Leica Microsystems Inc., Exton, PA, USA). For double dopamine D1DR and TH immunolabeling, the primary antibodies used were as follows: rat monoclonal anti-D1 receptor (D2944, $2 \mu \mathrm{g} / \mathrm{mL}$, SigmaAldrich, Stockholm, Sweden) and mouse monoclonal anti-TH $(2 \mu \mathrm{g} / \mathrm{mL}$, Diasorin AB, Sundbyberg, Sweden) antibodies. The D1DR antibody used recognizes 97 amino acids of the C-terminal of the human D1DR. The antidopamine D1 antibody (D2944) shows specificity by demonstration in HEK293T-27 immunoreactivity cells in singly transfected with $2 \mathrm{~g}$ of D1DR cDNA (cDNA.org) and no cross-reactivity in cells singly transfected with $2 \mathrm{~g}$ of D2DR cDNA (cDNA.org) (Supplementary Figure 1A). The secondary antibodies used were as follows: FITC-conjugated anti-rat IgG (Invitrogen, Stockholm, Sweden) and AlexaFluor® 594-conjugated anti-mouse IgG (Invitrogen). For double D2DR and TH immunolabeling, the primary antibodies used were as follows: rabbit polyclonal anti-D2 receptor (AB5084P, $2 \mu \mathrm{g} / \mathrm{mL}$, Millipore, Stockholm, Sweden) and mouse monoclonal anti-TH $(2 \mu \mathrm{g} / \mathrm{mL}$, Diasorin AB). The D2DR antibody used recognizes 28 amino acid within the third cytoplasmic loop of the human D2DR. The specificity of the anti-D2 receptor antibody (AB5084P) was validated in cells singly transfected with $2 \mathrm{~g}$ of D2DR or D1DR cDNA (cDNA.org). Cells singly transfected with D1DR cDNA do not show a cross-reactivity with the anti-dopamine D2 receptor antibody (AB5084P) (Supplementary Figure 1B). The secondary antibodies used were as follows: AlexaFluor® 488-conjugated anti-rabbit IgG (Invitrogen) and AlexaFluor ${ }^{\circledR}$ 594-conjugated anti-mouse IgG (Invitrogen). Images are shown as a single z-scan.

\section{Experiments with the Rapid-Golgi technique}

Animal experimentation and sacrifice were performed under the guidelines and with the approval of the Animal Research Committee of the Institute of Neurobiology (National Autonomous University of Mexico). Thirty adult (10-week-old) male rats were utilized for this part of the study. All animals were sacrificed by an overdose $(90 \mathrm{mg} / \mathrm{kg})$ of pentobarbital. The brain of each animal was dissected, and 3- to 4-mm-thick tissue specimens in either the sagittal or coronal plane were collected. Each specimen was immersed for 20 days in $3 \%$ potassium dichromate and $0.25 \%$ osmium tetroxide dissolved in water, followed by $12-20$ days in an aqueous solution of $0.75 \%$ silver nitrate. The tissue blocks were supported by an external shell of paraffin, and $150 \mu \mathrm{m}$ thick sections were cut at room temperature on a sliding microtome. Finally, the sections were left for $10 \mathrm{~min}$ in 70\% ethyl alcohol, dehydrated in graded solutions of propanolol/water, cleared in terpineol/xylene, mounted, and coverslipped.

\section{Experiments with the Golgi-Cox technique}

Brains from five animals were obtained and directly immersed for 25 weeks in a solution containing: $1 \%$ potassium dichromate, $0.8 \%$ potassium chromate, and 1\% mercuric chloride dissolved in deionized water. Three brains were cut sagittally and two horizontally into $140-\mu \mathrm{m}$ sections in a sliding microtome. Then, the sections were mounted on slides and immersed in a 1:65 dilution of T-Max (Kodak, Rochester, NY, USA) dissolved in deionized water for $30 \mathrm{~min}$, followed by a 15 -min fixation in rapid-fixer (Kodak) diluted 1:30 into water. The slides were left for $15 \mathrm{~min}$ in deionized water and counterstained with thionin. Lastly, sections were dehydrated in graded solutions of ethanol-water, cleared in terpineol-xylene, and coverslipped with resin.

\section{Results}

\section{Distribution pattern of D1DR immunofluorescence in the} arcuate-median eminence system and its partial co-distribution with tyrosine hydroxylase immunofluorescence

Lateral and medial part of the external layer of the median eminence (lateral and medial palisade zone)

A high density of punctate D1DR immunoreactivity (IR, in green) is found in the LPZ, while the density is low to modest in MPZ (Figure 1 $\mathrm{A}, \mathrm{B}$; Figure 2). In these figures the co-distribution of D1DR immunoreactive (IR) puncta with tyrosine hydroxylase IR nerve terminals (in red) is also demonstrated, as shown by the yellow color representing the overlap area of the two immunoreactivities (Figure 1A, lower panels). A similar architecture of these overlap areas was found in the LPZ on the other side of the median eminence (Figure 1B) and at different Bregma levels of the rat median eminence. In the MPZ of Figure 2, a partial colocalization of the green D1DR and red TH immunofluorescence can be clearly seen as small yellow patches of moderate densities extending into the central part of the median eminence (area of the deep capillary loops). In all parts of the medial median eminence including the subependymal and ependymal layers, the D1DR immunofluorescence also appeared to be present in cellular profiles with a morphology resembling tany- 

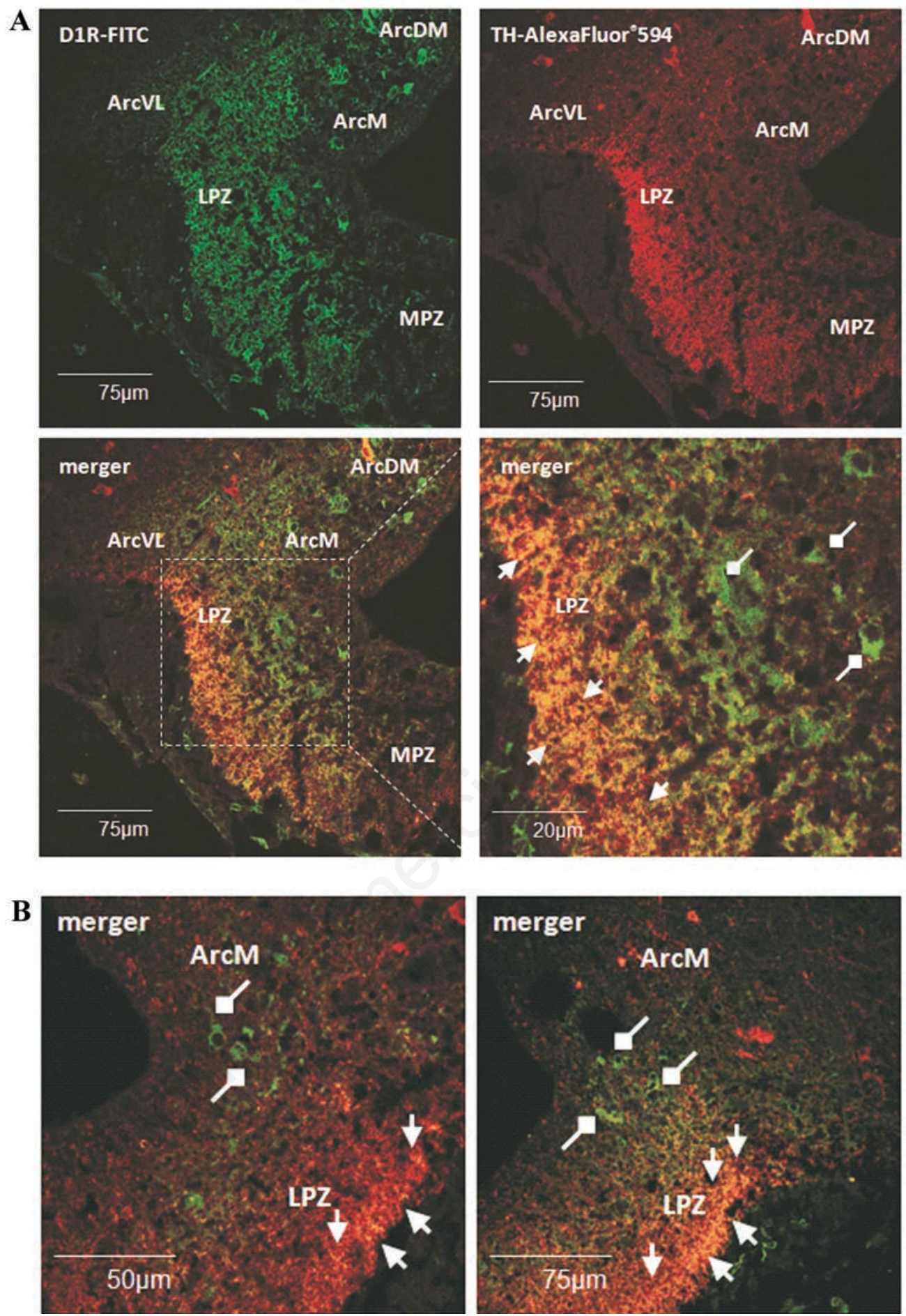

Figure 1. A) A high density of punctate D1DR (D1R) (in green) and tyrosine hydroxylase (TH) (in red) immunofluorescences is observed using double immunolabeling (upper panels) and shown to co-distribute (yellow-orange color upon merger, lower panels) within the lateral part of the external layer of the median eminence (LPZ, overlap area is indicated by arrows in lower right panel). A low density of punctate green D1R and red TH immunofluorescences is observed (upper panels) and appears to codistribute in the medial part of the external layer of the median eminence (MPZ, lower left panel). Green D1R cytoplasmatic immunofluorescence is observed in a cluster of nerve cell bodies of the internal layer in the lateral part of the median eminence. As examples, three of them are indicated by squares with lines (right lower panel); they are also found in the medial arcuate nucleus (ArcM, right panels); tey show no TH immunofluorescence (lower panels). The small DIDR IR nerve cell bodies observed in these regions potentially represent the small cells of the neuropeptide Y (NPY) IR nerve cell group known to exist in these regions. B) Similar observations are made on the other side of the arcuate-median eminence complex. Merger of D1DR (in green) and TH (in red) immunofluorescences show the codistribution (yellow-orange color upon merger) within the LPZ (overlap area outlined by arrows). Certain of the D1DR IR nerve cell bodies in the internal layer and in the ArcM are marked by squares with lines, potentially belonging to the neuropeptide Y (NPY) cell group. Images are representative for the three rats studied. ArcDM, arcuate nucleus, dorsomedial part; ArcM, arcuate nucleus, medial part; ArcVL, arcuate nucleus, ventrolateral part; LPZ, lateral palisade zone; MPZ, medial palisade zone. Bregma level: -3.14 mm. 


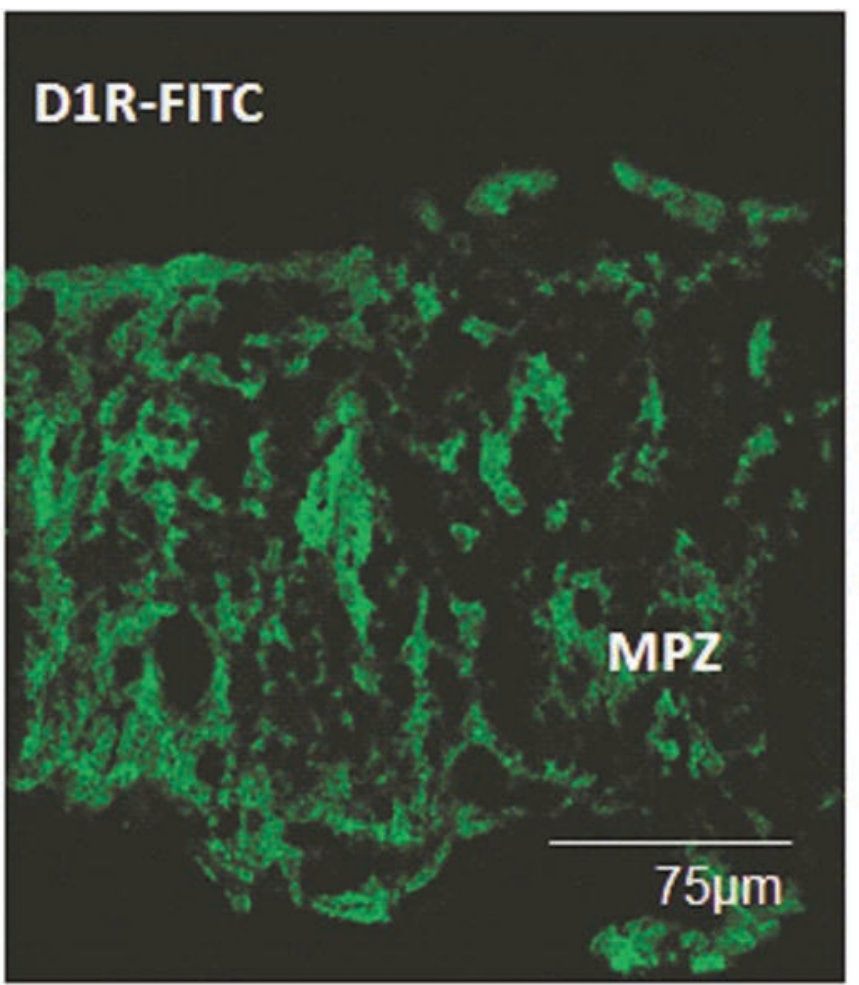

\section{TH-AlexaFluor 594}
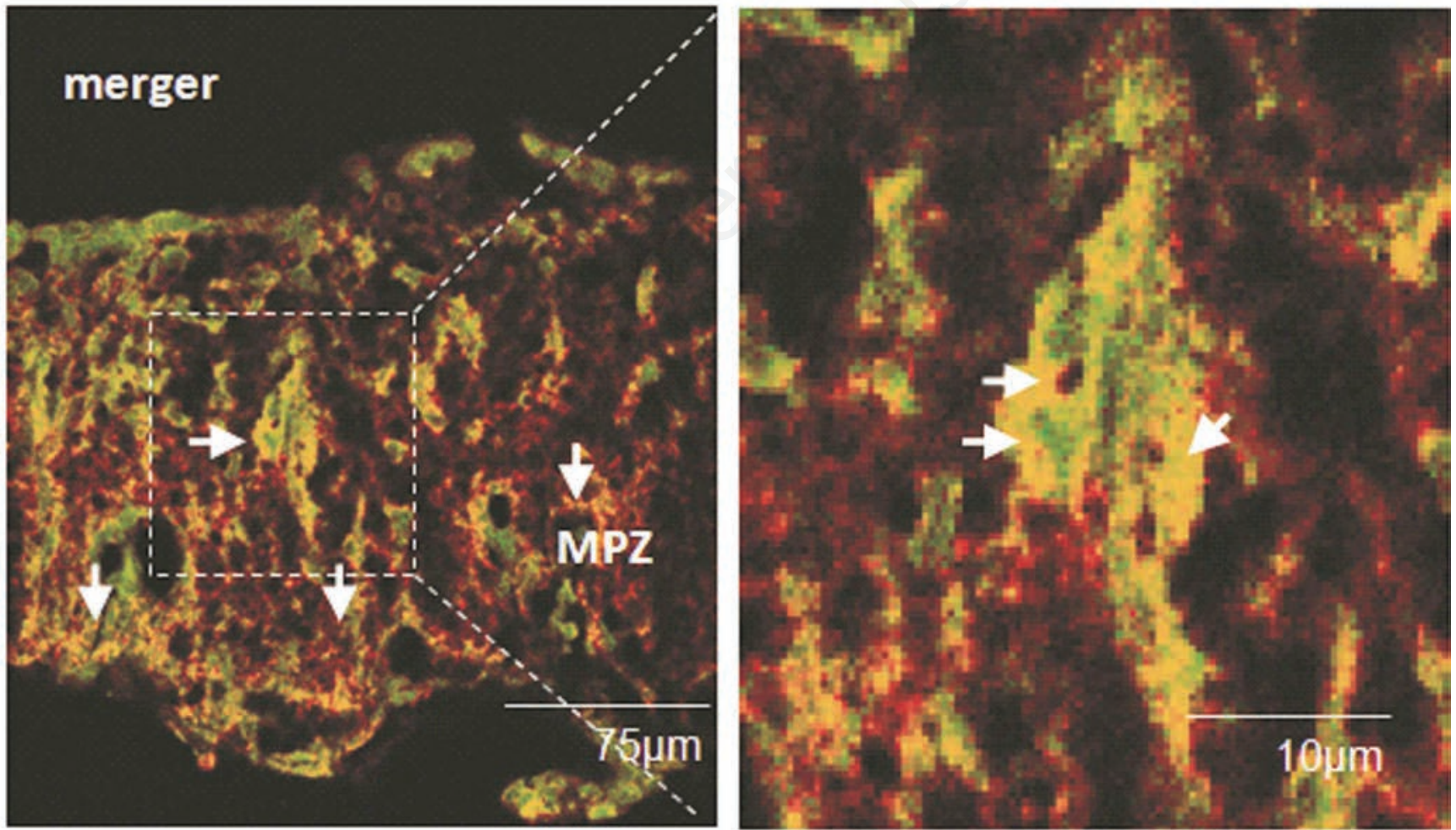

Figure 2. A partly punctate D1DR (D1R) immunofluorescence (in green) and tyrosine hydroxylase (TH) immunofluorescence (in red) of low to moderate density is observed in the medial part of the median eminence (MPZ). A merger of the two images demonstrates a substantial codistribution of the D1R and TH immunoreactivites (yellowish-orange color, see arrows). The D1DR immunofluorscence also appears to be located in cellular processes that may represent tanycytes some of which are approached by TH immunofluorescent nerve terminals. Images are representative for the three rats studied. MPZ, medial served palisade zone. Bregma levels upon merger: -3.14 mm. 
cytes. Certain D1DR positive cellular profiles seemed to have yellow overlap zones of green D1DR and red TH immunofluorescence in relation to their cell surface (Figure 2, arrows).

Internal layer of the median

eminence

As seen in Figure 1A, particularly in lower panels, a cluster of D1DR immunoreactive nerve cell bodies was found in the lateral part of the internal layer, observed also at several Bregma levels. They were also found in the matching area on the other side (Figure 1B). Double immunolabeling with D1DR and TH antibodies showed that these D1DR IR nerve cell bodies lacked TH IR (Figure 1 A,B). This region only sparsely contained TH IR nerve terminals indicating a low degree of innervation by catecholamine nerve terminals.

\section{Arcuate nucleus}

D1DR IR nerve cell bodies were mainly found in the ventromedial part of the arcuate nucleus located in continuity with the D1DR IR nerve cell bodies in the lateral part of the internal layer (Figure 1 A,B; Figure 3). Double immunolabeling also showed that these D1DR IR nerve cells lacked TH IR (Figure $1 \mathrm{~A}, \mathrm{~B}$; Figure 3). The same was true also for the few D1DR IR nerve cell bodies found in the ventrolateral arcuate nucleus where TH IR nerve cell bodies represent growth hormone releasing hormone containing nerve cells. ${ }^{13}$ In contrast, most scattered D1DR IR nerve cell bodies in the dorsomedial part of the arcuate nucleus, where the major DA/TH nerve cell group is found, ${ }^{13}$ where TH IR are visibile as yellow blobs or puncta in the diffusely red TH immunoreactive cytoplasm (Figure 3, arrows).

\section{Distribution pattern of D2DR immunofluorescence in the arcuate-median eminence system and its partial co-distribution with tyrosine hydroxylase immunofluo- rescence}

Lateral and medial part of the external layer of the median eminence (lateral and medial palisade zone)

The punctate green D2DR immunofluorescence was restricted to the lateral part of the LPZ (Figure 4), while the punctate red TH immunofluorescence in the DA nerve terminals occupied the entire LPZ (Figure 4). Double immunolabeling with the D2DR and TH antibodies demonstrated a complete overlap of the high density of punctate D2DR and TH immunoreactivites found in the D2 receptor positive part of LPZ. This was shown by the yellowish overlap area (Figure 4, lower panels). No D2DR immunofluorescent profiles were found in the internal layer nor in the subependymal layer. In the MPZ a low density of punctate green D2DR immunofluorescence was found in the most external part and in the capillary loop area, extending into the central part of the median eminence (Figure 5). The punctate red $\mathrm{TH}$ immunofluorescence in DA nerve terminals in the MPZ was of moderate density (Figure 4). Double TH-D2DR receptor immunolabeling revealed that many of the D2DR immunoreactive profiles co-distributed with the $\mathrm{TH}$ immunoreactive terminals as seen from the yellowish color that developed (Figure 5, lower panels). The red TH immunoreactive terminals were also found in the subependymal layer which appeared to lack the green punctate D2DR immunofluorescence (Figure 5).

\section{Arcuate nucleus}

In the dorsomedial arcuate nucleus a few nerve cell bodies with green D2DR immunofluorescence were shown (Figure 6), in spite of several TH immunoreactive nerve cell bodies present in the same field (Figure 6). With double immunolabeling the D2DR positive cell bodies were found to be TH immunoreactive. The D2DR immunoreactivity appeared as yellowish blobs in a diffuse red cytoplasmatic TH immunofluorescence (Figure 6). In the ventral periventricular hypothalamic regions continuous with the medial arcuate nucleus a substantial number of D2DR immunoreactive nerve cell bodies were demonstrated on one side, but not on the other (Figure 7). The reason may be that the section may have been obliquely cut, since the D2DR immunofluorescence only exist in discrete populations of the ventral periventricular region. Double immunolabeling procedures showed that all the D2DR immunoreactive nerve cell bodies were TH positive. Thus, the strong yellowish D2DR immunoreactive blobs were found in a sea of diffuse cytoplasmatic red TH immunofluorescence (Figure 7).

\section{Golgi analysis of the arcuate nucleus and the median eminence}

Survey camera lucida drawing from a horizontal section through the adult rat hypothalamus show the rostro-caudal extension of the arcuate nucleus close to the third ventricle (Figure 8). Sagittal sections adjacent to the third ventricle allow a better visualization of neurons and their processes in the arcuate nucleus (Arc). Most neurons of the Arc are bipolar having small (i.e., 12 to $16 \mu \mathrm{m}$ ) round to oval somata (Figure 9A). From the perikaryon paired dendrites proceed straight, usually in opposite directions. Dendritic shafts exhibit an uneven diameter due to the presence of numerous varicosities. The dendritic profile is generally smooth although occasional spines are sometimes seen. The thin axon of an Arc neuron arises from the cell body and follows an undulating trajectory along its ventral path. In successful impregnations where the complete axon is visualized it is evident that the distal part of the axon penetrates into the internal layer of the $\mathrm{ME}$, paralleling the numerous horizontal axons therein (Figure 9B). Like dendrites, the axon of the Arc neuron exhibits small, beaded tuberosities strung by the thin axon shaft. An important peculiarity is that the proximal (i.e., nuclear) axon lacks collaterals but as soon as it wins access to the ME domain, a massive collateralization occurs.

As shown in Figure 9C, the distal axon penetrates into the ME dorsal its caudal aspect and then it courses rostrally along its entire caudo-rostral extent. While the pattern of axonal collateralization is rather variable (Figure 9C, Figure 10B) three forms are frequently observed. A first, straight forward, manner is that of a single collateral proceeding transversally (Figure $10 \mathrm{C}, \mathrm{D}$ ). These single collaterals develop frequent varicosities both along the strand and at the distal end. The second type of collateral branching consists of a variable number of straight strands with varicosities arising from a short stem segment (Figure 10D). These strands proceed toward the external layer in parallel with each other. Still a third type of collateral is the one arising from a straight strand in either of the previously described collaterals (i.e., single or multiple) (Figure 10E).

\section{Discussion}

\section{Lateral palisade zone of the median eminence}

\section{D1 receptors}

One major finding of the current study is the first demonstration of a high density of punctate D1DR IR in the lateral palisade zone (LPZ) of the rat median eminence colocated with a high density of TH IR nerve terminals known to represent DA nerve terminals. ${ }^{2,21}$ These results are in line with previous work showing the existence of D1DR binding sites in the rat and sheep median eminence with D1DR radioligands using receptor autoradiography. ${ }^{15,22}$ Based on electron-microscopy, it was shown that LPZ is built up of a dense plexus of nerve terminals lacking synaptic contacts. ${ }^{18}$ Therefore, the punctate D1DR IR in the LPZ represents nerve terminals with D1DR IR shown to be codistributed with DA nerve terminals. It should be noted that one population of the D1DR positive terminals may be located on the DA nerve terminals of the tuberoinfundibular DA neurons. ${ }^{2}$ Thus, a large number of DA/TH cell bodies in the dorsomedial 
arcuate nucleus ${ }^{13}$ were for the first time demonstrated to contain both D1DR IR and TH IR. This proposal assumes that the D1DR may be transported from the DA cell bodies to the DA terminals of the external layer of the median eminence as described in the striato-nigral gamma-aminobutyric acids (GABA) neurons. ${ }^{23}$
Previous work indicated an inhibitory influence on LHRH IR terminals by DA terminals in the LPZ, ${ }^{6,12,14,24}$ which is supported by the current findings. We can now propose the existence of a D1DR mediated DA volume transmission $^{12,25}$ in the LPZ in view of the lack of synaptic contacts between nerve terminals of the LPZ. ${ }^{18}$ Thus, some D1DR may be located on LHRH IR terminals in the LPZ. We hypothesize that in the integrative DA/LHRH medianosomes the D1DR mediated VT may produce inhibition of LHRH release, based on previous works. ${ }^{12,25}$ It was observed that D1DR can inhibit the activation of the DA synthesis
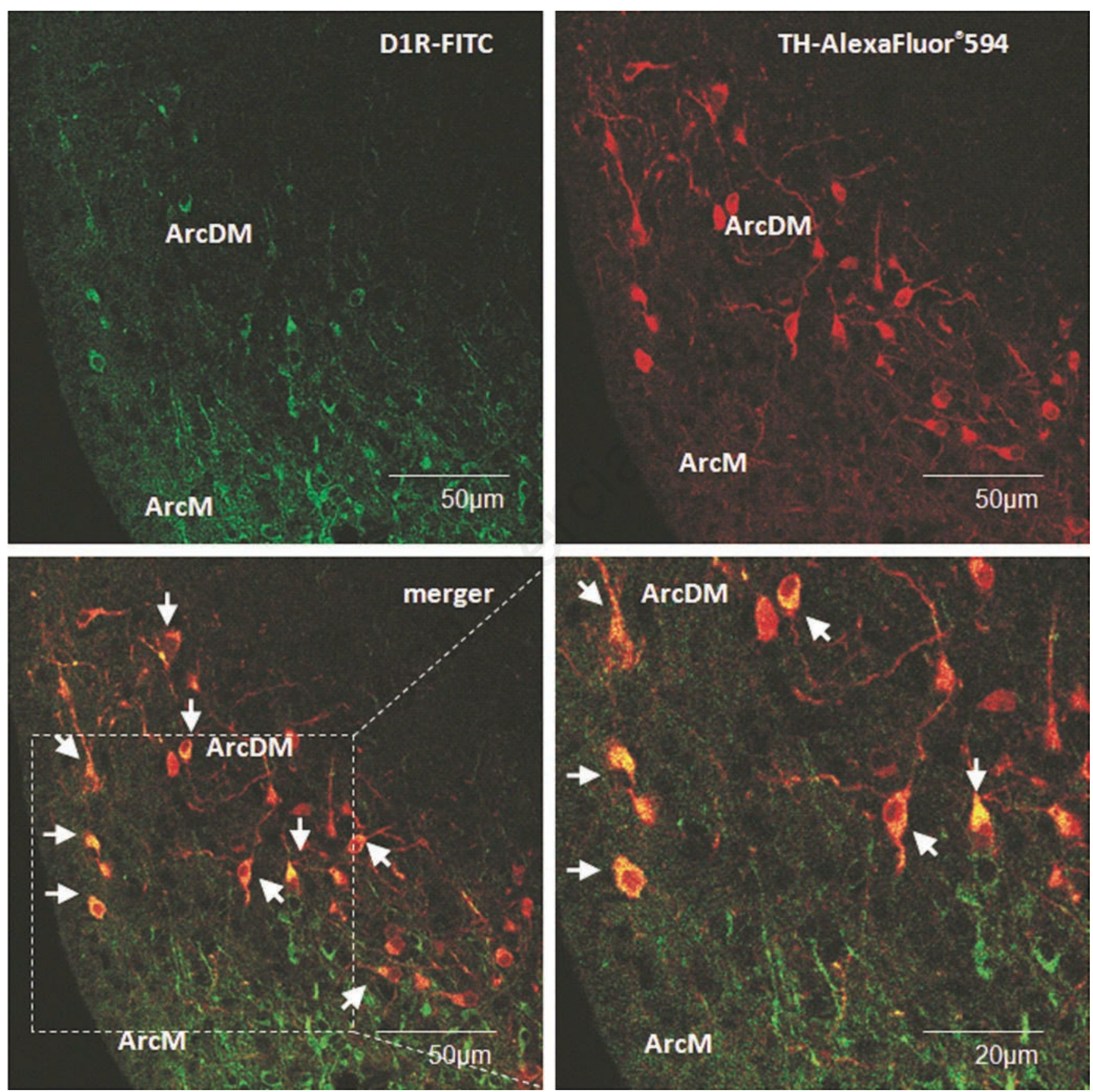

Figure 3. Punctate D1DR (D1R) (in green) and diffuse tyrosine hydroxylase (TH) (in red) immunofluorescences are mainly observed in groups of nerve cell bodies in the ventromedial (ArcM) and dorsomedial (ArcDM) parts of the arcuate nucleus, respectively (see all panels). Upon merger several nerve cell bodies in the dorsomedial part of the arcuate nucleus show coexistence of D1R and TH immunoreactivities (yellowish-orange color, see arrows). A yellowish punctate immunofluorescence is observed in the red cytoplsmatic TH immunofluorescence. Images representative for the three rats studied. ArcDM, arcuate nucleus, dorsomedial part; ArcM, arcuate nucleus, medial part. Bregma level: $-3.14 \mathrm{~mm}$. 
caused by increased tyrosine hydroxylase activity in the tubero-infundibular DA neurons as determined in studies on the accumulation of dihydroxyphenylalanine (DOPA) in the median eminence after inhibition of DOPA decarboxylase in vivo. ${ }^{26}$ It may therefore be that, in the D1DR positive tubero-infundibular DA neurons with D1DR at the cell-body level and potentially at the nerve terminal level, the role of their D1DR is to inhibit soma-dendritic DA synthesis and nerve terminal DA synthesis in the external layer of the median eminence. It may represent an inhibitory feedback mechanism on DA synthesis.

\section{D2 receptors}

A high density of a punctate D2DR immunofluorescence was also observed in the LPZ but restricted to a region in the far lateral part of the LPZ where it codistributed with the TH IR nerve terminals which are known to codistribute with the LHRH IR nerve terminals. ${ }^{5}$ It therefore seems possible that the D2DR IR observed in the LPZ is at least in part located on a population of LHRH IR nerve terminals. There also exists evidence based on the use of reverse microdialysis of D2DR agonists into the median

\section{TH-AlexaFluor@594}

\section{D2R-AlexaFluor@488}
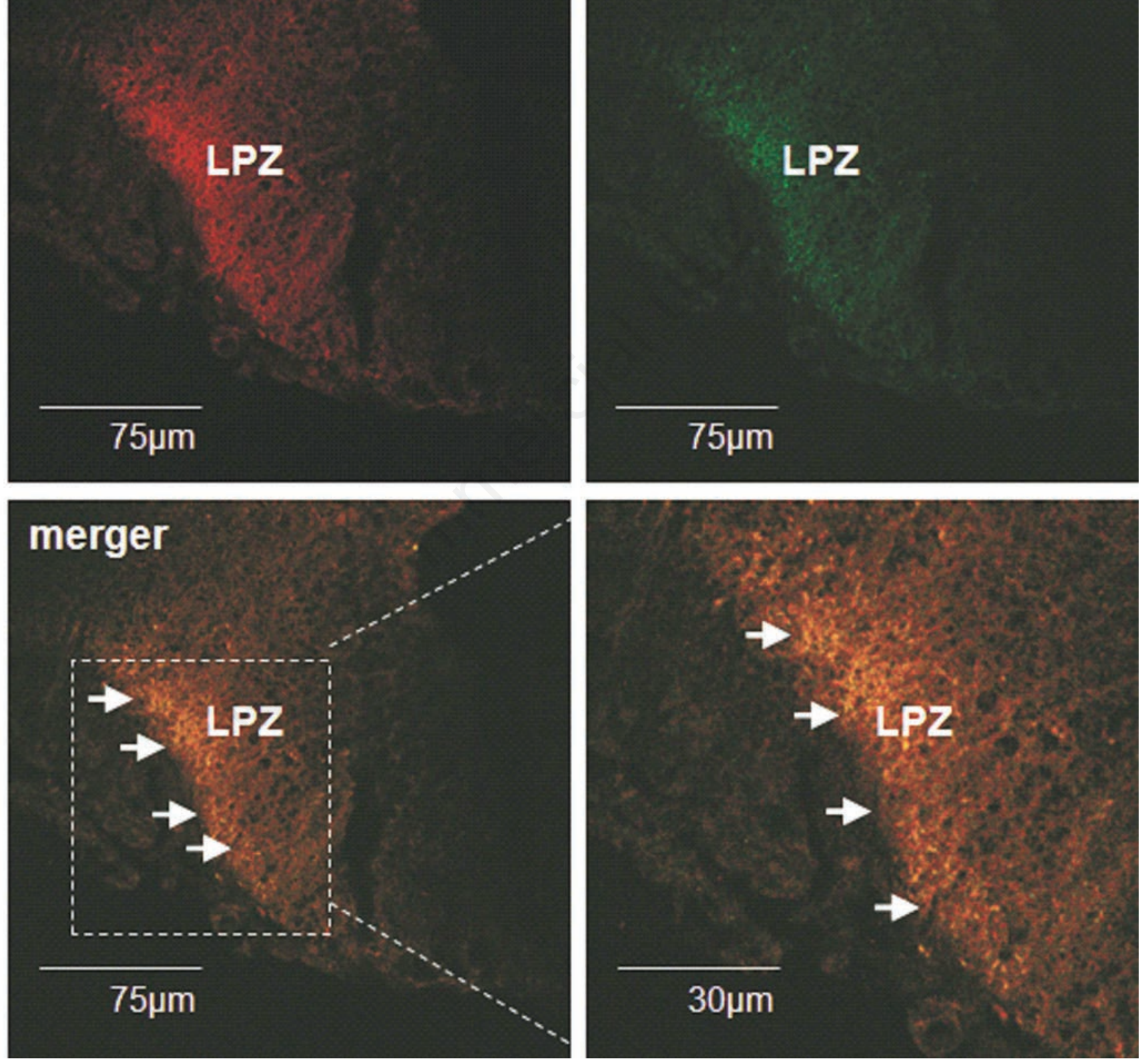

Figure 4. A restricted distribution of punctate D2DR (D2R) immunofluorescence (in green) is observed within the lateral part of the external layer of the median eminence (LPZ) vs the widespread punctate tyrosine hydroxylase immunofluorescence in the LPZ (in red). However, double immunolabeling shows a full overlap of the D2R immunoreactivity with the TH immunoreactivity as seen from the yellowish immunofluorescence that developed upon merger (overlap outlined by arrows). Images representative for the three rats studied. Bregma level: $-3.14 \mathrm{~mm}$. 
eminence of the ewe that D2DR but not D1DR in the median eminence establish long-day induced inhibition of LH secretion. ${ }^{17}$ Thus, it is possible that both D2DR and D1DR mechanisms in the LPZ can be in operation in the inhibitory control of LHRH secretion. It should be noted that D2DR agonists in contrast to
D1DR agonists increase DA synthesis and metabolism in the rat median eminence as determined from accumulation of DOPA after DOPA decarboxylase inhibition and measurement of DOPAC. ${ }^{27}$ These actions may in part be exerted directly on certain types of tuberoinfundibular DA neurons since part of the punc- tate D2DR IR can be located on DA terminals $\mathrm{x}(\mathrm{LPZ})$ and certain DA cell bodies of group A12 showed D2DR immunofluorescence, mainly in its ventral periventricular region. Such effects in the LPZ should further increase DA VT in this region and contribute to inhibition of LHRH release by D2DR agonists.

\section{TH-AlexaFluor®594}

\section{D2R-AlexaFluor@488}

\section{MPZ}
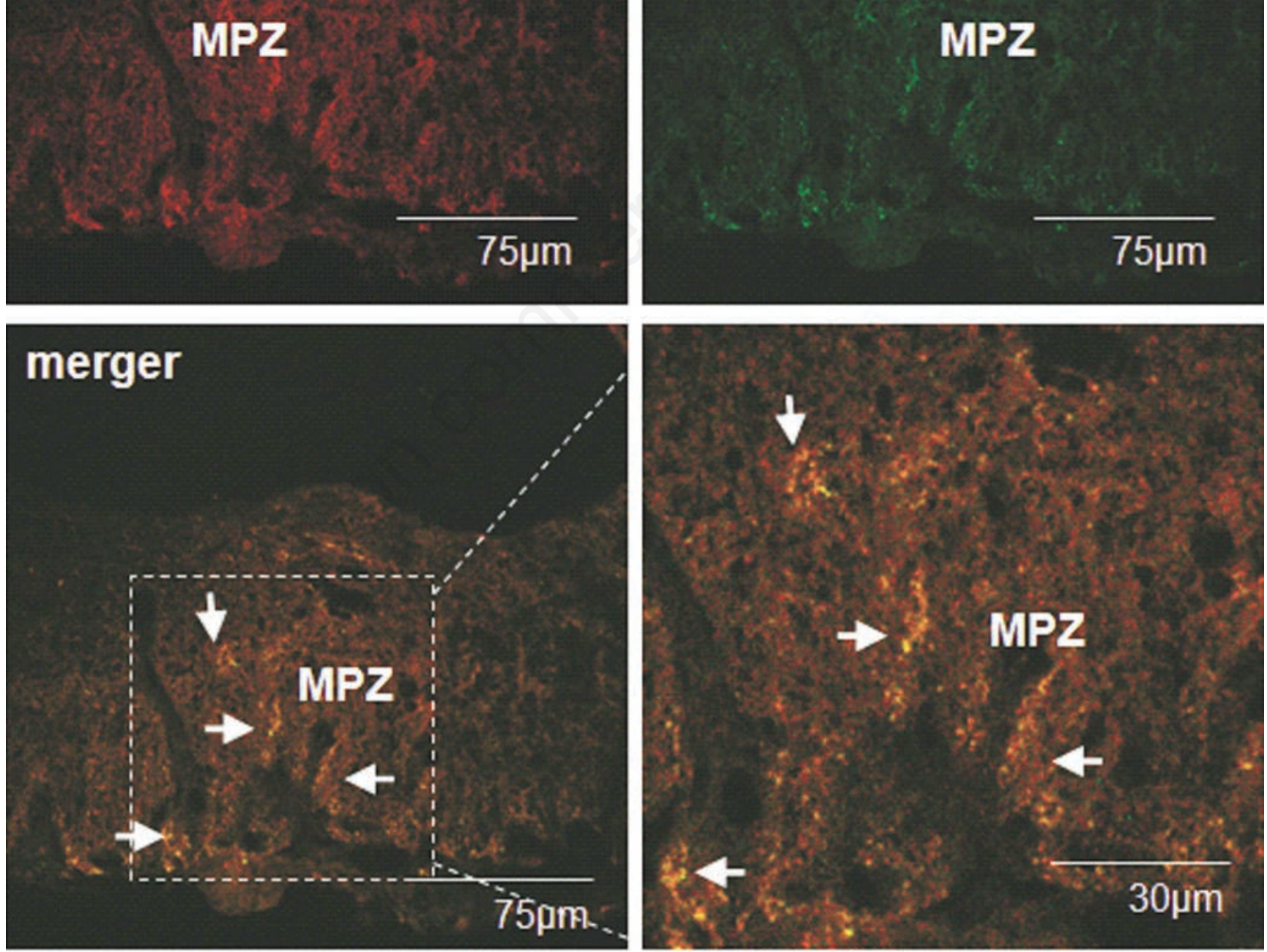

Figure 5. A low to moderate density of punctate D2DR (D2R) and tyrosine hydroxylase (TH) immunofluorescence is observed in the MPZ inter alia along the capillary loops. A high degree of codistribution is found as seen from the developed punctate yellowish immunofluorescence arrows. Images are representative for the three rats studied. Bregma level: $-3.14 \mathrm{~mm}$. 
Medial palisade zone of the median eminence

\section{D1 receptors}

The punctate D1DR IR in the medial palisade zone (MPZ) was observed to be only of a low to modest density, located close to the capillary loops of this region and was co-distributed with TH IR terminals, most of which are
DA nerve terminals, although NA terminals are also present. ${ }^{21}$ The tubero-infundibular DA neurons releasing DA as a prolactin inhibitory factor appears to mainly project to the MPZ, since rat prolactin (i.v.100 $\mu \mathrm{g} / \mathrm{kg}$ ) given acutely to the hypophysectomized rat increases DA turnover only in the MPZ. ${ }^{8,14}$ It is possible that the MPZ DA terminals may contain a prolactin receptor that may mediate an important feed- back mechanism to increase DA release as a prolactin inhibitory factor into the capillary loops of the portal vessels and bring down prolactin secretion. In addition, prolactin acts at a prolactin receptor at the soma level which changes the firing pattern of the tuberoinfundibular DA neurons leading to enhanced discharge and spike duration. ${ }^{28}$ Such an action likely also plays a relevant role in the prolactin

\section{TH-AlexaFluorß594}

\section{D2R-AlexaFluor@488}

\section{ArcDM}

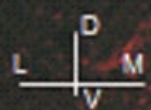

$75 \mu \mathrm{m}$

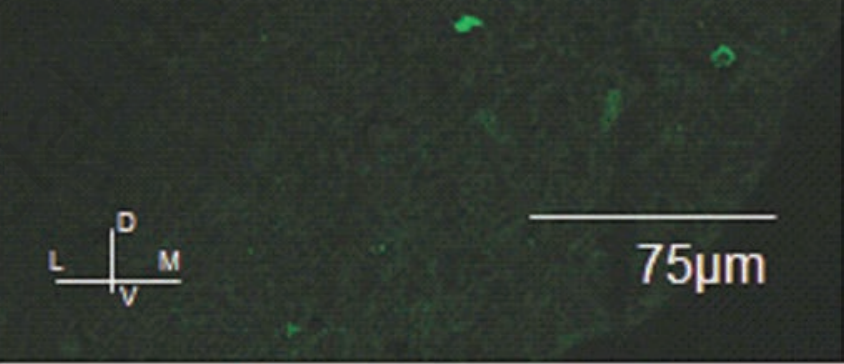

ArcDM

\section{merger}
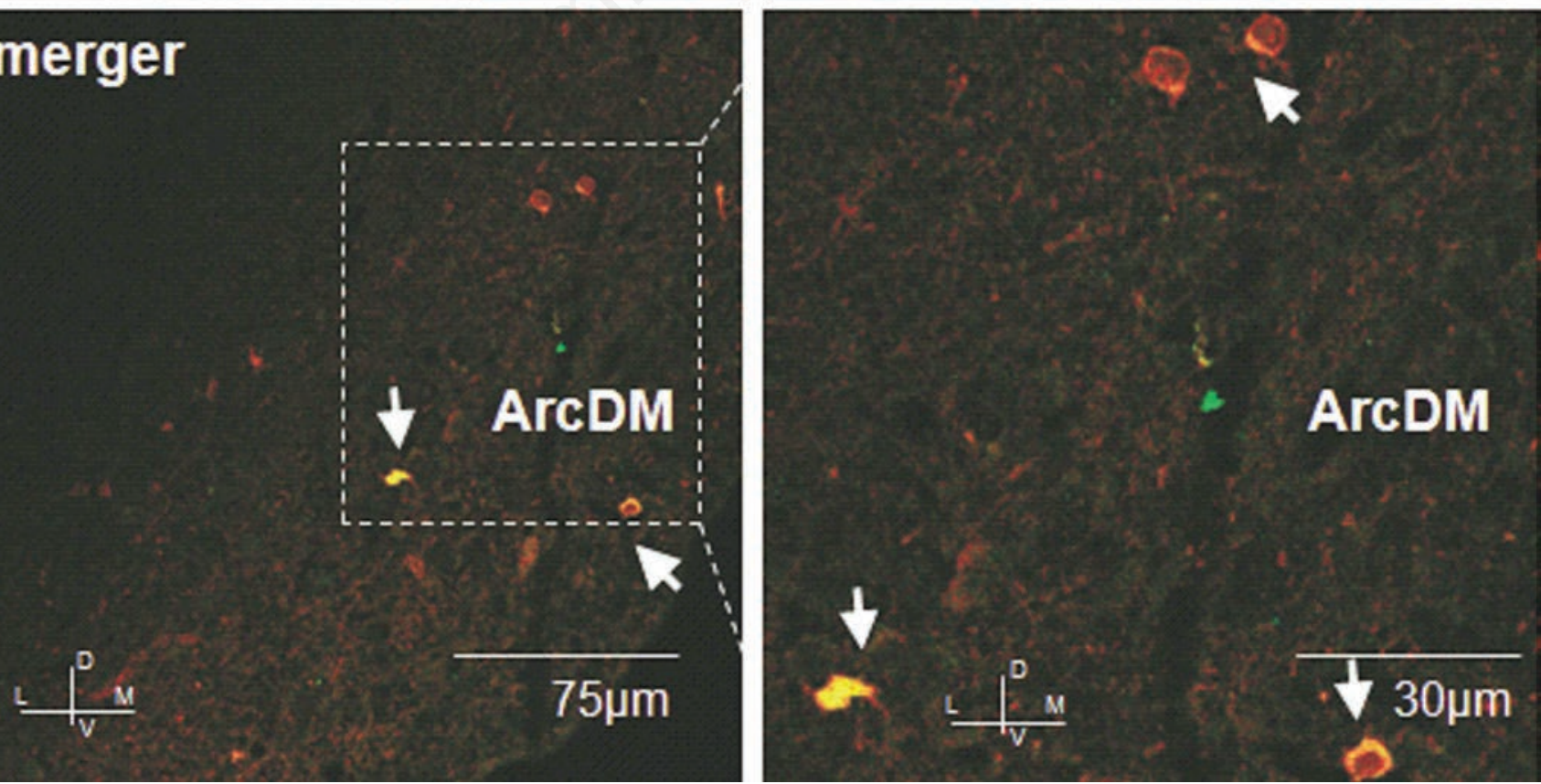

Figure 6. D2DR (D2R) and tyrosine hydroxylase immunoreactivities in double immunolabeled nerve cells are observed in low density among the tyrosine hydroxylase positive cells in the dorsomedial part of the arcuate nucleus (ArcDM, see arrows). Images are representative for the three rats studied. Bregma level: $-3.14 \mathrm{~mm}$. 
induced increase of MPZ DA turnover and release. It is unknown if the D1DR punctate IR in the MPZ is located on the MPZ DA terminals releasing DA as a prolactin inhibitory factor into the capillary loops and/or present on close by nerve terminals responding via D1DR to extracellular DA diffusing towards the capil- lary loops. However, it should be noted that substantial numbers of D1DR/TH immunoreactive nerve cell bodies in the dorsomedial arcuate nucleus are found in the current study known to represent DA cell bodies (see above). These results indicate that D1DR of the arcuate DA cell bodies can be transported down to their DA terminal networks in the external layer (see above). As discussed, Berry and Gudelsky ${ }^{26}$ found that D1DR activation can counteract DA synthesis in the median eminence. Such an action at MPZ DA nerve terminals containing putative D1DR would reduce the amounts of DA released and thus increase

\section{TH-AlexaFluor ${ }^{\circledR 594}$}

\section{D2R-AlexaFluor@488}

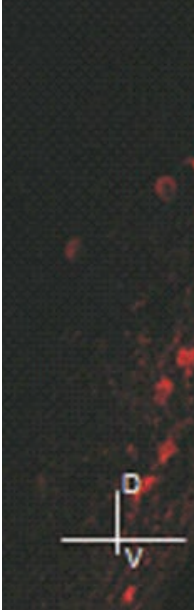

$$
\mathrm{Pe}
$$

\section{merger}
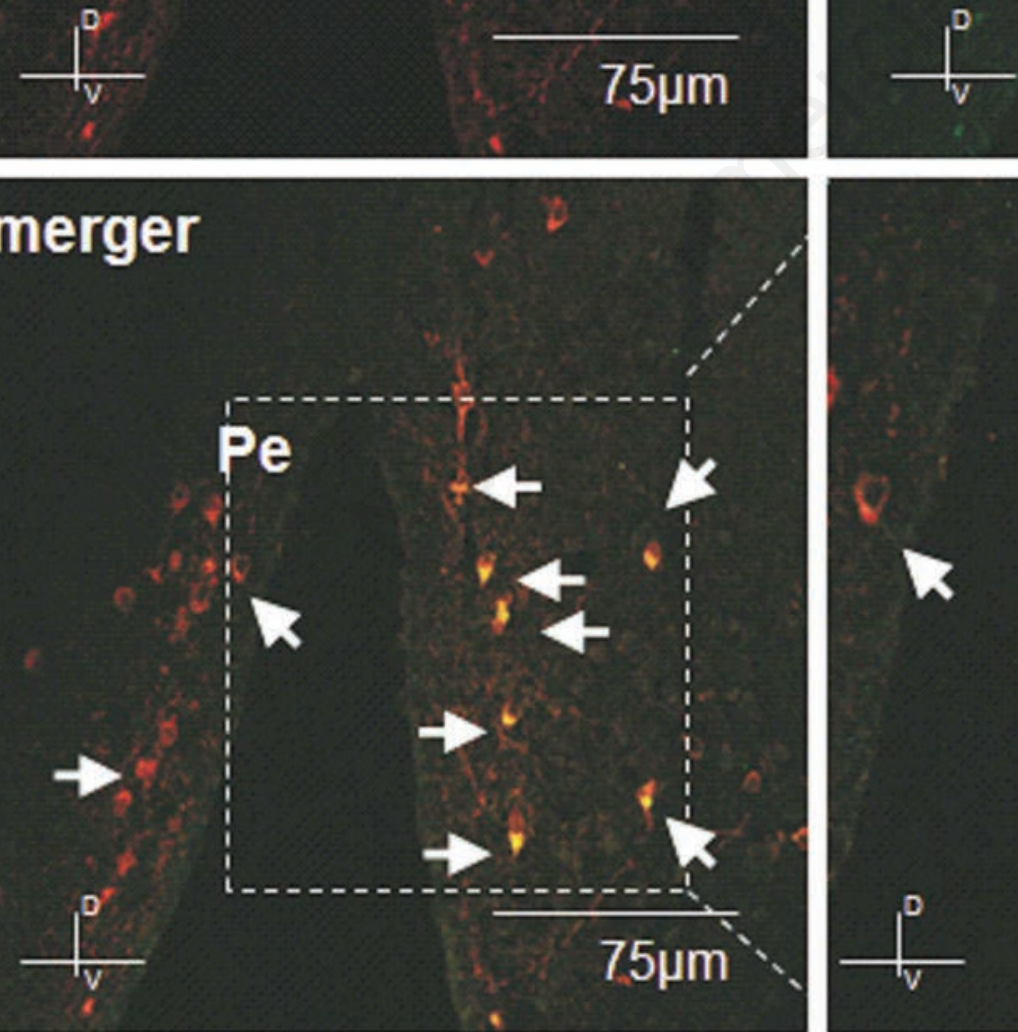

Figure 7. Punctate green Dopamine D2DR (D2R) receptor and diffuse cytoplasmatic red tyrosine hydroxylase immunofluorescences are observed in nerve cell bodies of the ventral periventricular hypothalamic region $(\mathrm{Pe})$ using double immunolabeling. They can coexist as seen from the punctate yellow-orange immunofluorescence that appears upon merger of the two images (see arrows). They are found to coexist in many nerve cells on one side but not on the other side probably due to an obliquely cut section leading to a different rostro-caudal level of the two sides arrows. Images are representative for the three rats studied. Bregma level: -3.14 mm. 
prolactin secretion. In the MPZ and the remaining layers of the medial median eminence (internal layer, subependymal layer), D1DR immunofluorescence was also observed in cellular profiles that may represent tanycytes known to contain a dopamine- and adenosine $\quad 3$ ':5'-monophosphate-regulated phosphoprotein (DARPP-32). ${ }^{29}$ The current results give support to the view that DA VT via D1DR may also directly regulate the function of tanycytes in the median eminence.

\section{D2 receptors}

A low density of punctate D2DR immunoflu- oresence was observed in the MPZ and the internal layer many of which colocalized with TH positive nerve terminals. It is therefore possible that D2DR can be located on DA terminals releasing DA as a prolactin inhibitory factor, since D2DR agonists enhance the synthesis and release of median eminence DA. ${ }^{27}$

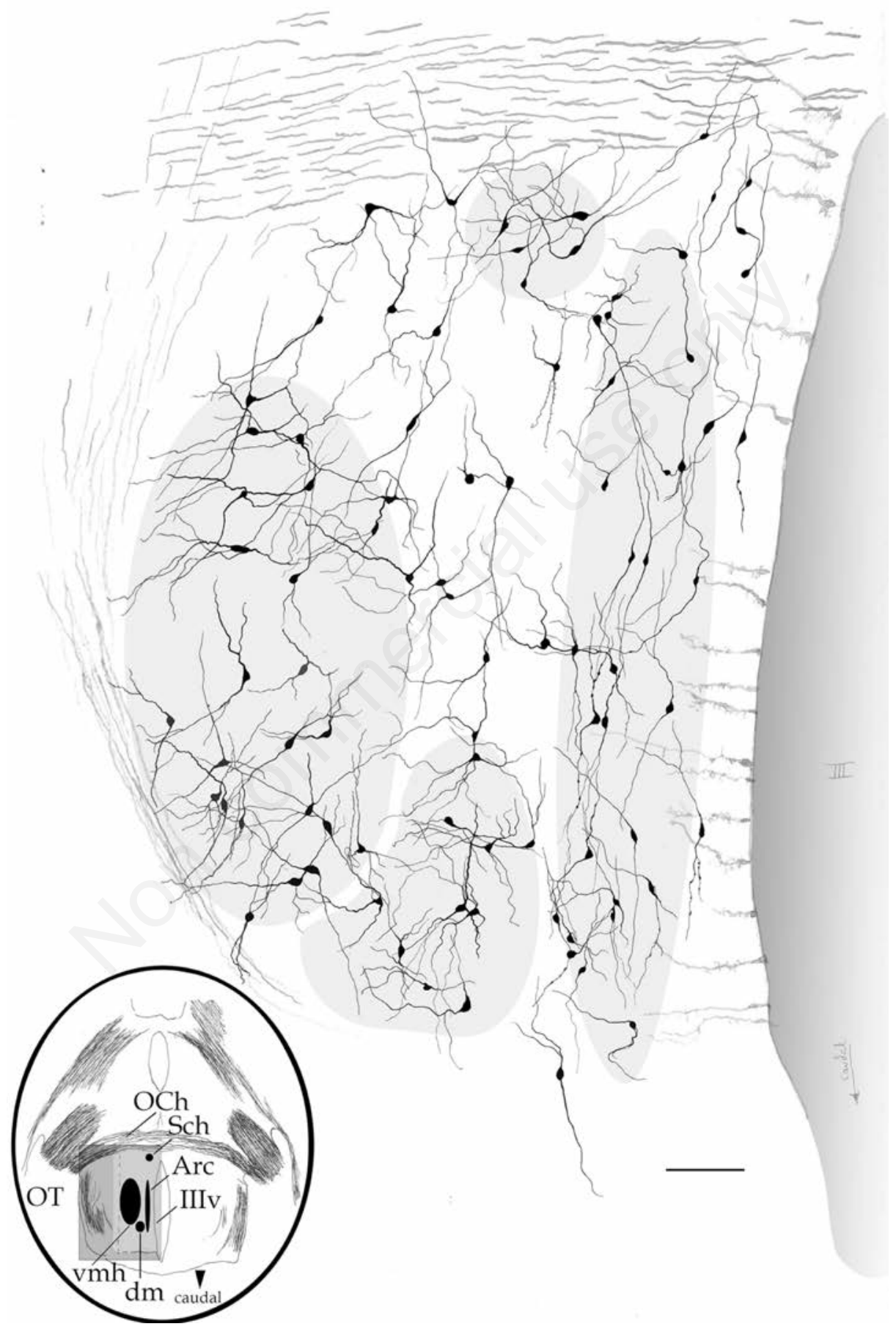

Figure 8. Down-left panel) Survey camera lucida drawing from a horizontal section through the adult rat hypothalamus. Fusiform neurons extending rostro-caudally compose the arcuate nucleus (Arc). Surrounding the Arc are the ventral portions of the ventro-medial (vmn), dorso-medial (dm), and suprachiasmtic (SCh) hypthalamic nuclei. OCh, optic tract; OCh, optic chiasm; IIIv, third ventricle. Golgi-Cox technique. Center-right up panel) High magnification drawings of the nucleic above. 

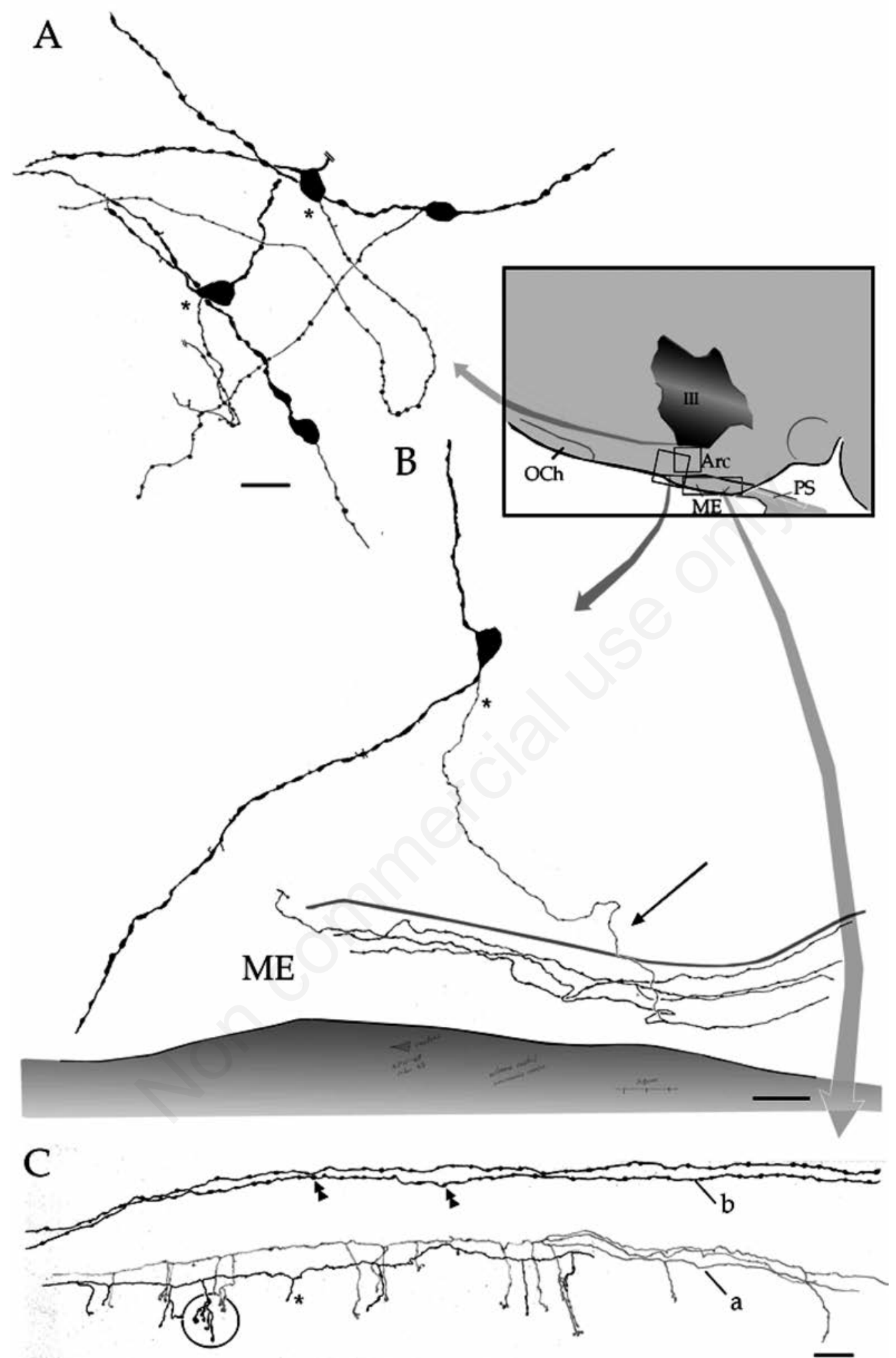

Figure 9. High magnification drawings from the arcuate nucleus-median eminence. A) Bi- and mono-polar neurons with descending axons (asterisks) in the arcuate nucleus; note the numerous tuberosities along the axonal shaft (red) as well as the overall divergent progression adopted by dendrites. B) A complete spindle shaped neuron whose axon (asterisk) descends penetrating (arrow) into the internal layer of the median eminence (ME). C) Internal layer of the median eminence; thick axons (b) of the neurohypophyseal tract with Herring bodies (arrow-heads) run in the internal layer deeper to those from other hypothalamic and preoptic nuclei (a); note that the latter two axons give rise to numerous single (asterisk) or multiple (encircled) collaterals resolving in terminal boutons within the external layer. Scale bars: $20 \mu \mathrm{m}$. Sagittal sections after the rapid-Golgi technique; adult rat brain. 

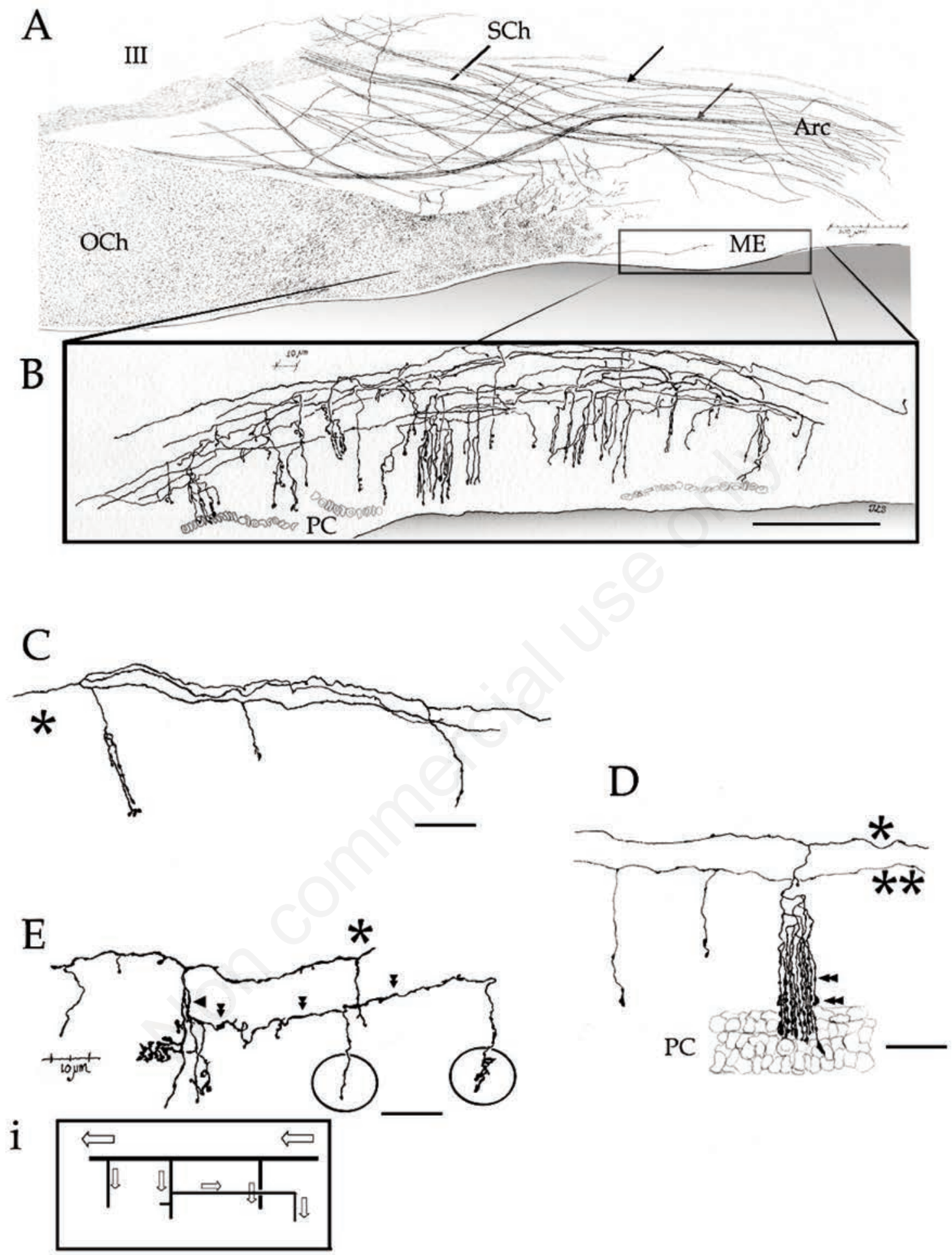

Figure 10. Camera lucida drawings from sagittal sections of the intersection between the ventral part of the hypothalamus and median eminence. A) Showing the position of the median eminence (ME) relative to the third ventricle (III), optic chiasm (OCh), arcuate (Arc), and suprachiasmatic (SC) nuclei; arrows, periventricular axons. B) Enlargement from the area boxed in (A); note that axons running rostro-caudally in the internal layer of the median eminence give rise to numerous collaterals that consists of single or several strands of nerve terminals; PC, portal blood vessels. C) An axon (asterisk) issues three collaterals, two of them appear as single strands of nerve terminals. D) A stem axon, running horizontally (asterisk) issues a collateral providing several rows of strands of terminals that display varicosities (double arrowhead); a second axon (double asterisk) issues successive single-strand collaterals (single arrowheads). E) A single axon (asterisk) sends out assorted collaterals; note that an ascending strand (arrowhead) originates a recurrent branch (double arrow heads) that, in turn, issues two strands of terminals. i) Diagram of the pattern of axonal ramification of the axon shown in (E); arrows point distally. Adult rat, rapid Golgi technique. Scale bars: A,B), $100 \mu \mathrm{m}$; C,E), $10 \mu \mathrm{m}$. 


\section{The structure of the arcuate- median eminence complex}

The current rapid-Golgi results from the arcuate-median eminence complex helps understand the structure of the tuberoinfundibular DA neurons. Although the neurovascular projection from the arcuate neuron to the external layer of the median eminence has been well-documented, ${ }^{3,4}$ our observations in Golgi-impregnated specimens provide the full structural picture for such interactions. Indeed, a set of small bipolar neurons in the arcuate nucleus issue descending axons that penetrate into the internal layer of the median eminence and run in a rostral-caudal direction. Collaterals are sent out from these axons in the internal layer to the external layer forming terminal networks contiguous to the capillary plexus of the portal vessels into which the hypothalamic hormones are released. Two types of nerve terminal plexa are observed; one which forms a single strand with varicosities and another which forms a distinct complex of several parallel strands with varicosities. These two basic types of nerve terminals are repeatedly issued along the parent axon to enter the external layer. There are indications that the LHRH IR collaterals can form single strands of varicose terminals in the external layer. ${ }^{30}$ Instead, the clusters of multiple strands of nerve terminals may represent the dopamine nerve terminals. Thus, ascending nigral DA axons are known to form collaterals transformed into a large number of varicose DA nerve terminals arborizing close to each other in the dorsal striatum..$^{31-33}$ Overall, it is assumed that the pattern of axonal organization described here between the proximal axon and terminal boutons issued by the arcuate neuron, bridges a fundamental gap between the earlier characterization of the arcuate neuron itself ${ }^{1}$ and the current mapping of the tridimensional reconstructs at the distal (i.e., vascular) end. ${ }^{34}$ These results bring structure to the immunohistochemically characterized arcuate neurons in this case the tubero-infundibular DA neurons.

In conclusion, the current results underline a role of especially D1DR but also of D2DR in the direct modulation of the tubero-infundibular DA neurons at the cell body and terminal level in the median eminence. A D1DR and D2DR mediated DA VT can exist in the LPZ directly inhibiting LHRH release from nerve terminals into the capillary plexus of the portal vessels. In the MPZ the major role of DA can be to be released into the portal system as a hypothalamic hormone to inhibit prolactin secretion. The D1DR and D2DR in the MPZ may differentially and directly modulate the secretion of DA as a prolactin inhibitory factor. The Golgi part of the study gives further indi- cations for the existence of tubero-infundibular neurons with an organized innervation of the external layer of the median eminence involving single or several parallel strands with varicosities formed from axon collaterals as the axons run in a horizontal plane in the internal layer of the median eminence.

\section{References}

1. Szentagothai JF, Flerkó B, Mess B, Halasz B. Hypothalamic control of the anterior pituitary function. Publishing House of the Hungarian Academy of Sciences, Budapest: 1968.

2. Fuxe K. Cellular localization of monoamines in the median eminence and the infundibular stem of some mammals. Z Zellforsch Mikrosk Anat 1964;61:710-24.

3. Merchenthaler I. Current status of brain hypophysiotropic factors: morphologic aspects. Trends Endocrinol Metab 1991;2: 219-26.

4. Zsarnovszky A, Naftolin F, Horvath TL. Estradiol affects axo-somatic contacts of neuroendocrine cells in the arcuate nucleus of adult rats. Neuroscience 2003;117: 791-4.

5. Agnati LF, Fuxe K, Hokfelt T, Goldstein M, Jeffcoate SL. A method to measure the distribution pattern of specific nerve terminals in sampled regions. Studies on tyrosine hydroxylase LHRH, TRH and GIH immunofluorescence. J Histochem Cytochem 1977;25:1222-36.

6. Fuxe K, Agnati LF, Zoli M, Biagini G, Cintra A, Eneroth P. Regulatory peptides in the neuroendocrine system, p. 31-69. In: M. Motta (ed.) Brain endocrinology. Raven press, New York: 1991.

7. Fuxe K, Lofstrom A, Hokfelt T, Ferland L, Andersson K, Agnati L, et al. Influence of central catecholamines on LHRH-containing pathways. Clin Obstet Gynaecol 1978;5: 251-69.

8. Andersson K, Fuxe K, Eneroth P, Nyberg F, Roos P. Rat prolactin and hypothalamic catecholamine nerve terminal systems. Evidence for rapid and discrete increases in dopamine and noradrenaline turnover in the hypophysectomized male rat. Eur J Pharmacol 1981;76:261-5.

9. Andersson K, Fuxe K, Agnati LF, Eneroth P, Camurri M. Luteinizing hormone-releasing hormone increases dopamine turnover in the lateral palisade zone of the median eminence and reduces noradrenaline turnover in the nuc. preopticus medialis of the hypophysectomized male rat. Neurosci Lett 1984;45:253-8.

10. Fuxe K, Andersson K, Harfstrand A, Agnati
LF, Eneroth P, Janson AM, et al. Medianosomes as integrative units in the external layer of the median eminence. Studies on grf/catecholamine and somatostatin/catecholamine interactions in the hypothalamus of the male rat. Neurochem Int 1986;9:155-70.

11. Fuxe K, Agnati LF, Kalia M, Goldstein M, Andersson K, Härfstrand A. Dopaminergic systems in the brain and pituitary, p. 1125. In: E. Flückiger E, E.E. Müller, M.O. Thorner (eds.) Basic and clinical aspects of neuroscience: the dopaminergic systems. Springer, Berlin: 1985.

12. Fuxe K, Agnati LF, Andersson K, Cintra A, Harfstrand A, Zoli M et al. D1 receptor mechanisms in the median eminence and their inhibitory regulation of LHRH release. Neurochem Int 1988; 13: 165-178.

13. Zoli M, Agnati LF, Tinner B, Steinbusch HW, Fuxe K. Distribution of dopamineimmunoreactive neurons and their relationships to transmitter and hypothalamic hormone-immunoreactive neuronal systems in the rat mediobasal hypothalamus. A morphometric and microdensitometric analysis. J Chem Neuroanat 1993;6:293310.

14. Fuxe K, Agnati LF, Bjelke B, Zoli M, Aguirre JA, Cintra A, et al. Central integration of chemical signals involved in the control of prolactin and LH secretion. Focus on the medianosomes. New Trends Gynaecol Obst 1991;7:237-59.

15. Fuxe K, Agnati LF, Benfenati F, Andersson K, Camurri M, Zoli M. Evidence for the existence of a dopamine receptor of the D1 type in the rat median eminence. Neurosci Lett 1983;43:185-90.

16. Fuxe K, Agnati LF, Harfstrand A, Zoli M, Eneroth P, Andersson K, et al. On the role of DA nerve terminals and tanycytes in the medianosomal or organization of the median eminence. Focus on the LHRH medianosome. Proceedings 6th Int. Catecholamine Symposium, Jerusalem: 1988.

17. Bertrand F, Thiery J, Picard S, Malpaux B. Implication of D2-like dopaminergic receptors in the median eminence during the establishment of long-day inhibition of LH secretion in the ewe. J Endocrinol 1999;163:243-54.

18. Ajika K. Relationship between catecholaminergic neurons and hypothalamic hormone-containing neurons in the hypothalamus, p. 1-32. In: Martini L, Ganong WF (eds.) Frontiers in neuro-endocrinology, vol. 6. Raven Press, New York: 1980

19. Fuxe K, Dahlstrom A, Hoistad M, Marcellino D, Jansson A, Rivera A, et al. From the Golgi-Cajal mapping to the transmitterbased characterization of the neuronal net- 
works leading to two modes of brain communication: wiring and volume transmission. Brain Res Rev 2007;55:17-54.

20. Borroto-Escuela D0, Romero-Fernandez W, Mudo G, Perez-Alea M, Ciruela F, Tarakanov A0, et al. Fibroblast growth factor receptor 1- 5-hydroxytryptamine $1 \mathrm{~A}$ heteroreceptor complexes and their enhancement of hippocampal plasticity. Biol Psychiatry 2012;71:84-91.

21. Lofstrom A, Jonsson G, Fuxe K. Microfluorimetric quantitation of catecholamine fluorescence in rat median eminence. I. Aspects on the distribution of dopamine and noradrenaline nerve terminals. J Histochem Cytochem 1976;24:415-29.

22. Colthorpe KL, Curlewis JD. Localization and characterization of dopamine D1 receptors in sheep hypothalamus and striatum. J Neuroendocrinol 1996;8:561-8.

23. Levey AI, Hersch SM, Rye DB, Sunahara RK, Niznik HB, Kitt CA, et al. Localization of D1 and D2 dopamine receptors in brain with subtype-specific antibodies. Proc Natl Acad Sci USA 1993;90:8861-5.

24. Fuxe K, Hokfelt T. On the existence of dopaminergic and noradrenergic mecha- nisms in the control of hormone releasing and inhibitory factor secretion from the median eminence. J Anat 1972;111:475-6.

25. Fuxe K, Agnati LF, Cintra A, Andersson K, Eneroth P, Harfstrand A et al. Studies on central D1 receptors role in volume transmission, neuroendrocrine regulation and release of noradrenaline. Adv Exp Med Biol 1988;235:83-119.

26. Berry SA, Gudelsky GA. D1 receptors function to inhibit the activation of tuberoinfundibular dopamine neurons. J Pharmacol Exp Ther 1990;254:677-82.

27. Berry SA, Gudelsky GA. Effect of D2 dopamine agonists on tuberoinfundibular dopamine neurons. Neuropharmacology 1991;30:961-5.

28. Lyons DJ, Hellysaz A, Broberger C. Prolactin regulates tuberoinfundibular dopamine neuron discharge pattern: novel feedback control mechanisms in the lactotrophic axis. J Neurosci 2012;32:8074-83.

29. Ouimet CC, Miller PE, Hemmings HC Jr, Walaas SI, Greengard P. DARPP-32, a dopamine- and adenosine 3':5'-monophosphate-regulated phosphoprotein enriched in dopamine-innervated brain regions. III.
Immunocytochemical localization. J Neurosci 1984;4:111-24.

30. Yin W, Mendenhall JM, Monita M, Gore AC. Three-dimensional properties of $\mathrm{GnRH}$ neuroterminals in the median eminence of young and old rats. J Comp Neurol 2009;517:284-95.

31. Anden NE, Carlsson A, Dahlstroem A, Fuxe K, Hillarp NA, Larsson K. Demonstration and Mapping out of Nigro-Neostriatal Dopamine Neurons. Life Sci 1964;3:523-30.

32. Anden NE, Hfuxe K, Hamberger B, Hokfelt T. A quantitative study on the nigro-neostriatal dopamine neuron system in the rat. Acta Physiol Scand 1966;67:306-12.

33. Olson L, Seiger A, Fuxe K. Heterogeneity of striatal and limbic dopamine innervation: highly fluorescent islands in developing and adult rats. Brain Res 1972;44:283-8.

34. Matsuyama S, Ohkura S, Mogi K, Wakabayashi Y, Mori Y, Tsukamura H, et al. Morphological evidence for direct interaction between kisspeptin and gonadotropin-releasing hormone neurons at the median eminence of the male goat: an immunoelectron microscopic study. Neuroendocrinology 2011;94:323-32. 